\title{
Creating Significant Learning Experiences for Clinical Reasoning by Physical Therapist Students
}

\author{
Lois A. Stickley
}

Texas State University, Lois.Stickley@txstate.edu

Follow this and additional works at: https://nsuworks.nova.edu/ijahsp

Part of the Medicine and Health Sciences Commons

\section{Recommended Citation}

Stickley LA. Creating Significant Learning Experiences for Clinical Reasoning by Physical Therapist Students. The Internet Journal of Allied Health Sciences and Practice. 2019 Jan 01;17(1), Article 4.

This Manuscript is brought to you for free and open access by the College of Health Care Sciences at NSUWorks. It has been accepted for inclusion in Internet Journal of Allied Health Sciences and Practice by an authorized editor of NSUWorks. For more information, please contact nsuworks@nova.edu. 


\title{
Creating Significant Learning Experiences for Clinical Reasoning by Physical Therapist Students
}

\begin{abstract}
Background: Clinical reasoning skills are embedded in all aspects of practice. There is a lack of consensus and standards for curriculum design and teaching methods of clinical reasoning in entry-level education of health professionals. Purpose: The purpose was to describe a process of designing one comprehensive, planned sequence of four courses to create significant learning experiences for clinical reasoning for Doctor of Physical Therapy students. Method: Fink's design process was used to develop four clinical decision-making courses to ensure a close alignment of learning goals, feedback and assessment, and learning activities to engage students in practicing components of clinical reasoning. Student outcomes were measured by self-efficacy ratings for clinical reasoning in a practical exam for first-year students and by ratings of performance by clinical instructors for third-year students. Results: 41 first-year students ranked their confidence in making clinical decisions both before and after a midterm practical. A paired t-test found a significant difference $\left(.05 t_{40}=-6.66, \rho=0.00\right)$ in the mean ratings of students from the prepractical assessment to the post-practical assessment about confidence in making clinical decisions. Third-year students received ratings that met or exceeded expectations on five audited skills from the Physical Therapist manual for the Assessment of Clinical Skills (PT MACS), both at midterm and at the final assessment. No significant differences between midterm and final ratings on any of the selected skills were found using a Chi-Square Test of Independence $(\alpha=.05)$. Conclusion: The four-course sequence was designed using four themes: patient-centered care, models of practice, and evidence-based practice, and ethics/legal issues. This paper offers specific details about how one method of teaching clinical reasoning meets the current trends in education and health care for accountability and meaningful outcomes. Students gained practical knowledge and skills in the components of clinical reasoning and decisionmaking by participating in active and engaging significant learning experiences.
\end{abstract}

\section{Author Bio(s)}

Lois Stickley, PT, PhD is an Associate Professor in the College of Health Professions, Department of Physical Therapy at Texas State University in Round Rock, TX. She is also a licensed physical therapist. 


\title{
IIIAHSP ${ }^{m}$ \\ The Internet Journal of Allied Health Sciences and Practice \\ Dedicated to allied health professional practice and education \\ Vol. 17 No. 1 ISSN 1540-580X \\ Creating Significant Learning Experiences for Clinical Reasoning by Physical Therapist Students
}

\author{
Lois Stickley, PhD, PT \\ Texas State University \\ United States
}

\begin{abstract}
Background: Clinical reasoning skills are embedded in all aspects of practice. There is a lack of consensus and standards for curriculum design and teaching methods of clinical reasoning in entry-level education of health professionals. Purpose: The purpose was to describe a process of designing one comprehensive, planned sequence of four courses to create significant learning experiences for clinical reasoning for Doctor of Physical Therapy students. Method: Fink's design process was used to develop four clinical decision-making courses to ensure a close alignment of learning goals, feedback and assessment, and learning activities to engage students in practicing components of clinical reasoning. Student outcomes were measured by selfefficacy ratings for clinical reasoning in a practical exam for first-year students and by ratings of performance by clinical instructors for third-year students. Results: 41 first-year students ranked their confidence in making clinical decisions both before and after a midterm practical. A paired t-test found a significant difference $\left(.05 t_{40}=-6.66, \rho=0.00\right)$ in the mean ratings of students from the pre-practical assessment to the post-practical assessment about confidence in making clinical decisions. Third-year students received ratings that met or exceeded expectations on five audited skills from the Physical Therapist Manual for the Assessment of Clinical Skills (PT MACS), both at midterm and at the final assessment. No significant differences between midterm and final ratings on any of the selected skills were found using a Chi-Square Test of Independence $(\alpha=.05)$. Conclusion: The four-course sequence was designed using four themes: patient-centered care, models of practice, and evidence-based practice, and ethics/legal issues. This paper offers specific details about how one method of teaching clinical reasoning meets the current trends in education and health care for accountability and meaningful outcomes. Students gained practical knowledge and skills in the components of clinical reasoning and decision-making by participating in active and engaging significant learning experiences.
\end{abstract}

Keywords: professional education, physical therapist education, teaching methods, clinical reasoning, clinical decision making, curriculum design 


\section{INTRODUCTION}

The ability to make the most appropriate decisions about patient management through clinical reasoning is necessary for effective and efficient patient-centered practice across all health professions. ${ }^{1}$ The Clinical Reasoning Curricula and Assessment Research Consortium (CRARC) of the American Council of Academic Physical Therapy identified many different definitions of and synonyms for clinical reasoning, including clinical decision-making and clinical judgment. Their consensus definition is:

"Clinical reasoning is a nonlinear, recursive cognitive process in which the clinician synthesizes information collaboratively with the patient, caregivers, and the health care team in the context of the task and the setting. The clinician reflectively integrates information with previous knowledge and best available evidence in order to take deliberative action."2

Clinical reasoning skills are embedded in all aspects of practice for health professionals including professional identity, philosophy of practice, professional skills and techniques, communication, collaboration, and ethics. ${ }^{3}$ Jones, Jensen, and Edwards identified five dimensions of clinical reasoning: cognition and metacognition, a specific knowledge base, self-awareness, recognizing the role of the patient in the decision-making process, and the specific context in which the reasoning occurs. ${ }^{4}$ These five dimensions apply to clinical reasoning used by all health care professionals, additionally clinicians must have a working knowledge of the core values of their profession, how to apply a code of ethics, and the legal requirements to practice in their profession. ${ }^{4}$

Published literature documented a myriad of different approaches to teach clinical reasoning skills and the CRARC recognized a lack of consensus and standards for curriculum design, teaching methods, and assessment of clinical reasoning in entry-level education of physical therapists. ${ }^{2}$ Two clinical reasoning models used in physical therapist practice and educational programs are the Patient/Client Management Model described in the Guide to Physical Therapist Practice (Guide) and the Hypothesis-Oriented Algorithm for Clinicians II (HOAC II)5,6. The International Classification of Functioning, Disability, and Health (ICF) is utilized in both the Guide and the HOAC II to organize patient impairments, functional limitations, and participation restrictions. ${ }^{7}$

A recent study by Christiansen et al. surveyed 207 directors of accredited professional physical therapist programs and reported results from 96 respondents (return rate 46.4\%). Almost all respondents (98\%) reported using one or more of the following frameworks for teaching clinical reasoning: The Guide $(93.8 \%, n=90)$, the ICF $(93.8 \%, n=90)$, and the HOAC II $(55.2 \%, n=53)$. The survey found that assessment of clinical reasoning in the programs included practical examinations (99\%), clinical coursework (94.8\%), written examinations (87.5\%), and written assignments (83.3\%). ${ }^{2} \mathrm{~A}$ study by Ryan and Higgs suggested incorporating guided observations, thought-provoking readings, thinking aloud during the reasoning process, reviewing videos of demonstrated clinical reasoning, and reflective writing. ${ }^{8}$ Another way to assess clinical reasoning is through self-efficacy.

Self-efficacy is a person's belief about his or her capability to perform at a certain level for a specific task. Self-efficacy differs from self-confidence, as self-confidence is a more global concept indicating the strength of belief a person has about his or her self, but not related to a specific task. ${ }^{4}$ Strength of perceived self-efficacy is not necessarily linearly related to behaviors but the stronger the sense of self-efficacy, the greater the perseverance and the higher the likelihood that the chosen activity will be performed successfully. ${ }^{9}$

Fink developed a curriculum design process intended to move students beyond lower levels of learning, such as remembering and understanding facts, to achieve higher levels of learning such as analysis, evaluation, and creation. He identified the importance of planning for active and significant learning experiences in all domains of learning. Fink proposed that significant learning experiences are those that result in active student engagement and lasting change in the student that exist beyond the end of the course. ${ }^{10-13}$ Fink's approach to designing significant learning experiences was a learner-centered model versus a teacher-centered model. He proposed a taxonomy of learning based on Bloom's hierarchical taxonomy but expanded it to include noncognitive components. The components of Fink's taxonomy were (a) foundational knowledge (understanding and remembering information and ideas), (b) application of skills, critical thinking, managing projects (c) integration (connecting ideas, learning experiences, and realms of life) (d) human dimension (reflecting on oneself and others), (e) caring (development of new feelings, interests, and values), and (f) learning how to learn (becoming a better student, inquiry, and self-directed learners). ${ }^{10}$ Another difference from Bloom's taxonomy is that Fink's taxonomy was circular, rather than hierarchical, emphasizing the inter-relatedness of each aspect. ${ }^{13}$

Fink described his approach to creating significant learning experiences as occurring in reverse order compared to traditional course design methods. Most educators plan how and what they will teach, then develop assessment methods which are often limited to written exams, and finally identify learning goals. Fink advocated identifying the learning goals first, then identifying how

( The Internet Journal of Allied Health Sciences and Practice, 2019 
student learning will be assessed, and finally identifying and designing learning experiences. ${ }^{10,12,13}$ Fink's design process consisted of three phases and 12 steps to develop an integrated course design.

\section{Initial Phase: Build Strong Primary Components}

Step 1: Identify important situational factors. This initial step included identifying course content, the context in which the course will be taught, any specific or unusual characteristics of students and instructors, and accreditation or other external group expectations. ${ }^{10}$

Step 2: Identify important learning goals. Learning goals establish what the instructor wants the student to learn from the course within the six dimensions in Fink's taxonomy of learning. Fink recommended writing no more than seven or eight significant learning goals which represent each of the six dimensions of learning. ${ }^{10-12}$

Step 3: Formulate appropriate feedback and assessment procedures. Fink asserted that assessment does not add to student learning unless it provides useful information about what the student did as part of a significant learning experience. This type of assessment required evidence of student judgment and innovation in simulated or real-life contexts. High quality feedback should be provided frequently and as soon as possible after the product is delivered. It should also be discriminating and delivered in a supportive manner. ${ }^{10-12} \mathrm{~A}$ range of feedback and assessment procedures should be used to ensure that all learning goals are being achieved. Examples of assessments that could be used in the health professions include documentation review, objective standardized clinical evaluation (OSCE), oral patient presentations, practical lab assessments, and self-assessment. ${ }^{12}$

Step 4: Select effective teaching and learning activities. Fink advocated that active learning is required for learning to be significant. This means minimizing passive reception of information from reading or lectures. Instead active learning focuses on doing and observing, then reflecting on what was learned and how it was learned. ${ }^{10,11}$ Instructors of health care professionals should incorporate activities that occur regularly in professional practice, for example evaluating a real or simulated patient, designing and implementing interventions, and documenting patient management. Instructional methods could include case-based learning, clinical experiences, group discussions, journal clubs, observations of patient management by experts, simulations, and reflection. ${ }^{12}$

Step 5: Make sure the primary components are integrated. In this step a schedule of the course is developed to ensure integration of the learning goals with assessment and the active learning experiences. ${ }^{10}$

\section{Intermediate Phase: Assemble the Components into a Coherent Whole}

Step 6: Create a thematic structure for the course. Themes are used to organize the course in a logical order. Themes can be arranged sequentially or concurrently with each theme extending over several class meetings. ${ }^{10}$

Step 7: Select or create a teaching strategy. Fink describes a teaching strategy as a specific combination of learning activities presented in a sequence. ${ }^{10}$ For example in health care, a teaching strategy could involve following a patient through an episode of care, so in this case themes might be interwoven and presented concurrently within the patient case.

Step 8: Integrate the course structure and the instructional strategy to create an overall scheme of learning activities. This step requires the instructor to plan activities for each class meeting. To integrate the content, Fink recommended using a variety of learning activities, presenting activities to build complexity as students gain knowledge and skills, and integrating topics throughout the course in each learning unit. ${ }^{10}$

Final Phase: Finish Important Remaining Tasks

Step 9: Develop a grading system. The grading system must be educationally significant. The graded items should be diverse and reflect the full range of learning goals. The weight of the graded items should demonstrate their importance relative to the learning goals. ${ }^{10}$

Step 10: Debug the possible problems. A critical review of the course design may identify potential problems that can be avoided. For example, is there adequate time for student to complete learning activities and graded assignments? ${ }^{10}$

Step 11: Write the course syllabus. Many departments have specific requirements for course syllabi and there are many different styles that could be incorporated. No matter which style is used, it is essential to provide enough information so that students are clear about what they will be doing and how they will be assessed.10 
Step 12: Plan an evaluation of the course and of your teaching. In additional to required end-of-course student evaluations include other ways for the instructor to receive feedback about the course and teaching effectiveness. For example, a midterm course evaluation gives students the opportunity to provide feedback that can modify the course while they are taking it, not for the next cohort. The use of peer reviews given in an honest and supportive manner can be invaluable, as can reviewing a recording of a class to view objectively what happened in class. ${ }^{10}$

Fink's significant learning approach focused on creating optimal learning environments for students, not on improving teaching techniques. Traditional course designs focus on passive learning and summative assessments and are easy to replicate. By contrast Fink focused on active learning and timely and relevant feedback and assessment. ${ }^{10,11}$

Since clinical reasoning is a core of clinical practice, it also should be a foundation of a professional curriculum. Ryan and Higgs recommend incorporating clinical reasoning into the entire curriculum, which requires significant faculty commitment. ${ }^{8}$ Christiansen et al. reported that $90 \%$ of the programs they surveyed integrated clinical reasoning throughout their curriculum while only $29 \%$ included a stand-alone course in clinical reasoning. ${ }^{2}$ The purpose of this paper is to describe the design of a planned sequence of courses to teach clinical reasoning to professional physical therapist students using Fink's curriculum design process. A secondary purpose is to present student outcomes related to the clinical reasoning process.

\section{METHOD: COURSE-SEQUENCE DEVELOPMENT}

The Doctor of Physical Therapy curriculum at Texas State University was designed to include a sequence of four courses focused on clinical reasoning and decision-making. In adopting this curriculum, the faculty demonstrated their belief in the importance and value of teaching clinical reasoning and decision-making in the professional program. In the deliberative process of redeveloping the sequence and individual courses, the curriculum design process described by Fink was used. The four-course Clinical Decision Making (CDM) sequence was designed to facilitate a planned and methodical integration of all concepts and skills learned by the students to that point in the curriculum, provide opportunities to apply clinical reasoning and judgment, and practice psychomotor skills.

Fink's design process was used to develop the clinical decision-making courses to ensure a close alignment of learning goals, feedback and assessment, and learning activities to engage students in practicing components of clinical decision-making. This report describes Phases I and II of the process. ${ }^{10}$

\section{Initial Phase: Build Strong Primary Components}

Step 1: Analysis of Situational Factors. The Doctor of Physical Therapy is a three-year, nine-semester program which admits one cohort to matriculate each summer session. The sequence of CDM courses was taught to approximately 40 graduate (doctoral) students in each cohort. Learner characteristics included graduate students mainly in their mid-20s to mid-30s who came from a variety of socioeconomic and cultural backgrounds. The students met weekly for three-hour blocks in a combined classroom and laboratory setting. The courses were co-taught by two faculty members who were licensed physical therapists, each with more than 30 years of experience in a variety of patient care settings, one of whom held a PhD in Adult Education and the other held an MS in Special Education.

Step 2: Identification of Learning Goals of the Sequence. The sequence of CDM courses had five significant learning goals which represented each of the six dimensions of learning in Fink's taxonomy. ${ }^{10}$ The primary goal of the sequence was to enhance the clinical reasoning skills and quality of clinical decisions made by the students. The significant learning goals for the sequence are what the instructors wanted students to retain after the course was completed and which changed the students in a real and long-lasting manner. ${ }^{10}$ Using a single set of goals for the sequence helped to unify the courses and provided links to learning experiences that provided active practice of tasks that are expected of graduates of physical therapy professional programs. The five significant learning goals for the sequence were that students would:

1. demonstrate clinical reasoning skills and sound clinical decisions in physical therapist practice (Dimensions: Foundational knowledge, Application, and Integration)

2. use a model of clinical practice to apply current knowledge and skills to patient cases (Dimensions: Application, and Integration)

3. practice using a patient-centered focus (Dimensions: Integration, Human dimension, and Caring)

4. use current best evidence to support decisions about patient management (Dimensions: Foundational knowledge, Application, Integration, and Learning how-to-learn)

5. practice in a legal or ethical manner (Dimensions: Foundational knowledge, Application, Integration, Human dimensions, and Caring) 
Appendix A describes the objectives for each individual course that support the five goals of the sequence.

Step 3: Identification of Methods of Feedback and Assessment. Student learning was evaluated by projects and assignments that were clinically significant and relevant including analysis of patient cases using the Guide or the HOAC-II, linking examination findings with goals and interventions, and developing interventions using current evidence of best practices. Other methods of assessment included documenting patient care, developing patient education materials, and reflecting on observations of expert practice and their own performance.

Step 4: Identification of Learning Experiences. Learning experiences focused on integrating the knowledge and skills that students had gained in the curriculum up to that point in time, not on providing new information. Most of the learning experiences focused around patient cases and observing or working with patient volunteers from the community. In CDM-I, students worked with case studies which represented a range of individuals of different ages from various ethnic, religious, and socioeconomic backgrounds. As the semester progressed students received more information about the cases and advanced from performing initial evaluations, to providing daily treatments, teaching home exercise programs, and completing discharge evaluations. In the following three courses (CDM II - IV), students observed expert practitioners evaluating and treating volunteer patients. The experts "talked aloud" to reveal their clinical reasoning, then students analyzed and documented the data from the observation and planned intervention strategies. In the following class periods, students worked with similar cases which were purposefully linked to other courses that the students were concurrently taking to allow integration and application of concepts and psychomotor skills being learned each semester. The cases progressed in the sequence from simple to more complex and included multiple venues of care from acute care to outpatient settings.

In CDM-I, students worked through patient cases in small groups and practiced psychomotor skills by demonstrating examination and intervention techniques. Students then documented their clinical decisions-making skills for patient care using worksheets based on the model of practice described in the Guide and that incorporated the ICF.., 7 See Appendix B for an example worksheet. The HOAC II was incorporated in CDM II-IV and learning experiences reflected a more complete, complex model of practice. ${ }^{6}$

Learning experiences that involved student role-playing were done in triads. One student played the role of the patient while a second student played the physical therapist. The third student was an observer who was assigned specific questions to think about while observing the interaction making this an active learning experience. ${ }^{14}$ The student playing the role of the physical therapist first self-assessed his or her own performance, then the "patient" provided feedback, and finally the observer provided specific feedback to the "therapist" about her or his communication and interpersonal skills, the selection and performance of interventions, and clinical decisions. This process facilitated self-assessment and reflection, which are vital in the development of clinical reasoning skills, for all students. ${ }^{1,2}$

Step 5: Integration of Learning and Assessment. Many learning experiences allowed the students to engage in individual and small group problem-solving activities followed by reflection and assessment of student learning. Figure 1 shows how learning and assessment are intertwined in a typical unit of learning. In this example, students were given a reading assignment to be completed before the first class in the unit. A readiness assignment, in which students answered two to three questions about the reading, ensured that students were prepared for active learning during the class period. The first class period began with small group discussion about the reading assignment, then an expert clinician provided a demonstration of a patient examination and evaluation while stating aloud their thoughts about the decisions they made. In the second class period, students practiced examination and evaluation in a role-playing format for a case. The assessment for this learning experience had students document the examination and evaluation, which was used to asses their clinical reasoning. Before the final class in the unit, students identified current literature that identified best practices for the patient's diagnosis. In groups of three, they coordinated the findings of the articles and planned and then carried out an intervention. Students practiced reflection and self-assessment and provided peer assessment about the provision of the intervention. The learning assessment associated with this activity was a worksheet in which student linked the patient's problems, goals, and specific interventions. This example shows how the course instructor designed assessments that were clinical and meaningful significant and that were closely linked to the learning activities. The unit in this example included learning assessments of documentation of patient care; strategies to link patient problems, goals, and interventions; analysis of peer-reviewed literature; and reflections on observations of expert practitioners and the student's own performance.

(c) The Internet Journal of Allied Health Sciences and Practice, 2019 


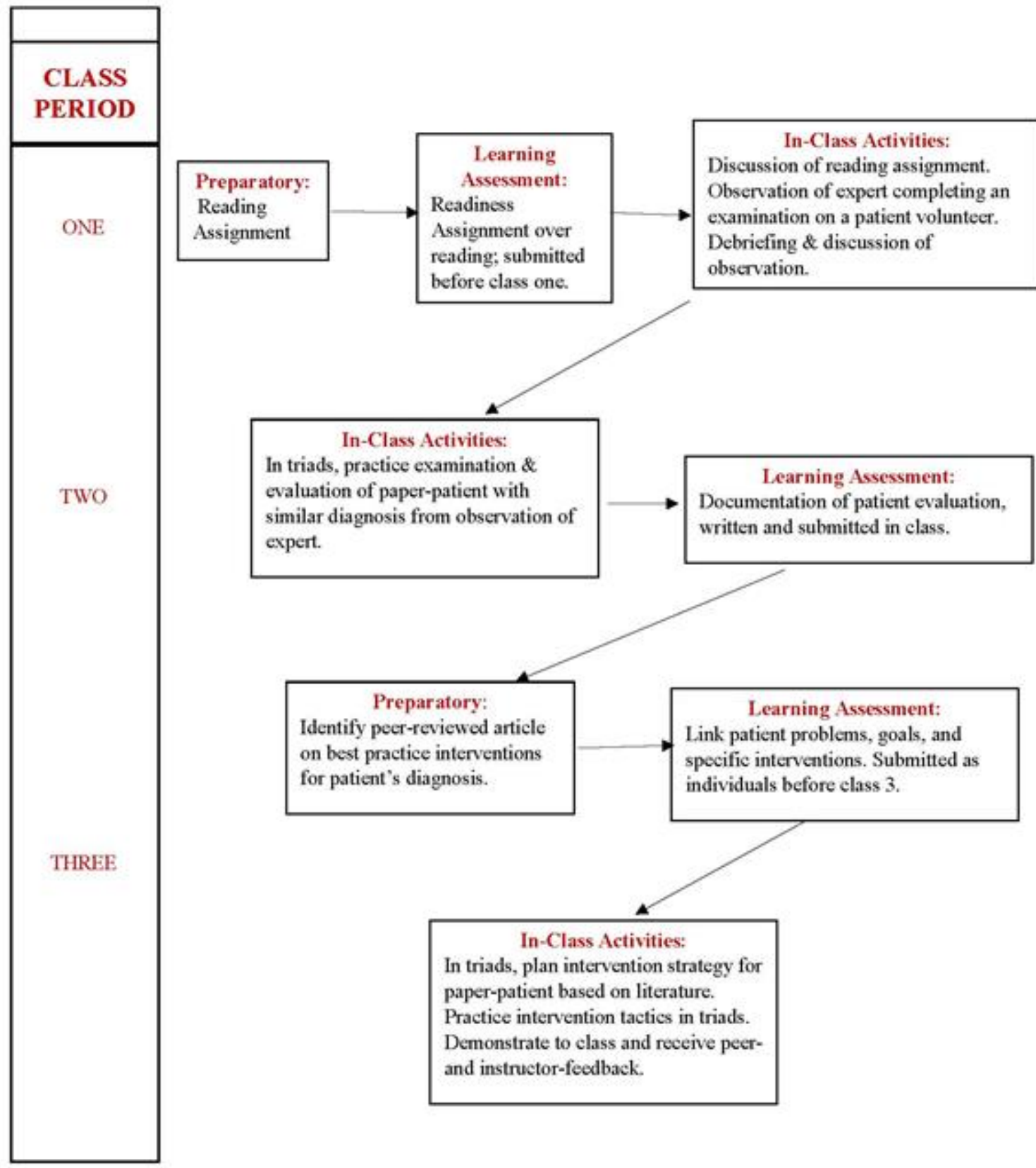

Figure 1. Example of integration of learning and assessment

\section{Intermediate Phase: Assemble the Components into a Coherent Whole}

Step 6: Create a thematic structure for the courses. Learning experiences in all CDM courses were focused around four themes: model of practice, patient-centered care, evidence-based practice, and ethics and legal responsibilities. These concepts about clinical reasoning were consistently present in the literature and along with the CRARC definition of clinical reasoning were used to develop the themes for the CDM sequence. ${ }^{1-5}$ Additionally, ten expected outcomes for physical therapist graduates identified by Grignon et al. in 2014 were used to identify the themes. The outcomes were service and social responsibility, professionalism, professional role, professional commitment, practice management, communication, professional growth and development, evidence-based practice, clinical reasoning, and patient management. ${ }^{15}$

Incorporating a model of clinical practice was the first theme and was supported by the concepts of having a philosophy of practice and facilitating cognition and metacognition. ${ }^{2-4}$ This theme also was supported by Grignon's expected graduate outcome of patient 
management. ${ }^{15}$ The second theme of patient-centered care included the concepts of having a philosophy of practice, communication and collaboration, ethics, self-awareness, and most importantly recognizing the patient in the decision-making process. $^{2-4}$ The evidence-based practice (EBP) theme was based on Jewell's definition of evidence-based physical therapist practice as "open and thoughtful clinical decision making about physical therapist management of a patient or client that integrates the best available evidence with clinical judgment and the patient or client's preferences and values, and that further considers the larger social context in which physical therapy services are provided, to optimize patient or client outcomes and quality of life."16 The EBP theme was supported by Jewell's definition and other concepts from the literature of having a specific knowledge base and recognizing the patient in the decision-making process and also was identified as an expected outcome of graduates by Grignon. 2,15 The final theme of ethical and legal responsibilities incorporated concepts of ethics, professional identity, selfawareness, and communication and collaboration. ${ }^{3,4}$ Expected outcomes that support the ethical and legal responsibilities theme included service and social responsibility, professionalism, professional role, professional commitment, and practice management. ${ }^{15}$

These four themes: model of practice, patient-centered care, evidence-based practice, and ethics/legal issues, were used to provide structure and integration in the clinical decision-making courses both within each course and throughout the sequence. Each theme was developed across the entire course sequence, advancing in both complexity and in depth. See Table 1 for an example of the course structure for CDM-I. The sequence was designed to help the students learn theoretical foundations and understand the process of clinical reasoning, experience and gain understanding of clinical reasoning in action, and reflect on their reasoning to continue to develop those abilities. ${ }^{8}$

Model of Clinical Practice: Two models of clinical practice were used as a framework to guide the students through the patient management process. The Guide was used in CDM I to introduce students to a patient management model and to allow early practice of clinical reasoning. The HOAC II was used as a framework for practice in CDM-II through IV because the HOAC II describes a more detailed and complex process of patient management than the Guide. Both models emphasize the clinical expertise and judgment of the physical therapist in making the clinical decisions to provide efficient and efficacious care. The patient is the center of both models and emphasize that all decisions should be made collaboratively with the patient. 5,6

Patient-Centered Care: One of the key characteristics of expert practitioners is that they use a patient-centered approach and that the patient is an active participant in learning about their health issues and how to solve or manage them. ${ }^{1}$ The Institute of Medicine (IOM) defines patient-centered care as care that is "respectful of and responsive to individual patient preferences, needs, and values and ensures that patient values guide all clinical decisions." ${ }^{17}$ Physical therapist practice is centered on the individual patient and patients are considered an important source of knowledge for patient management, helping the clinician to identify impairments, functional limitations, and participation restrictions as well as meaningful goals. ${ }^{1,2}$ In the CDM sequence, patientcentered learning experiences included the individual context in which patients live such as culture, age, and socioeconomic backgrounds. The emphasis was on how the individual context of the patient cases could influence their clinical presentation, examination, prognosis, and intervention.

In CDM-IV students and faculty volunteered to share information about their personal backgrounds if they had emigrated from a different country, were from a family that maintained their original ethnic cultural traditions or had a unique community tie such as the military. The presentations focused on health beliefs and behaviors and basic and health-related communication skills. In this course, students also participated in a "book club" designed to increase their awareness of the individual experience of illness and disability. Students chose one book to read from a list of over 20 books identified by the instructor. After reading the book, students wrote a paper reflecting on their own thoughts and emotions about the character's experience and projecting how they might handle a similar situation, then the students discussed the books in small groups. 
Table 1. Example of CDM-I Course Structure

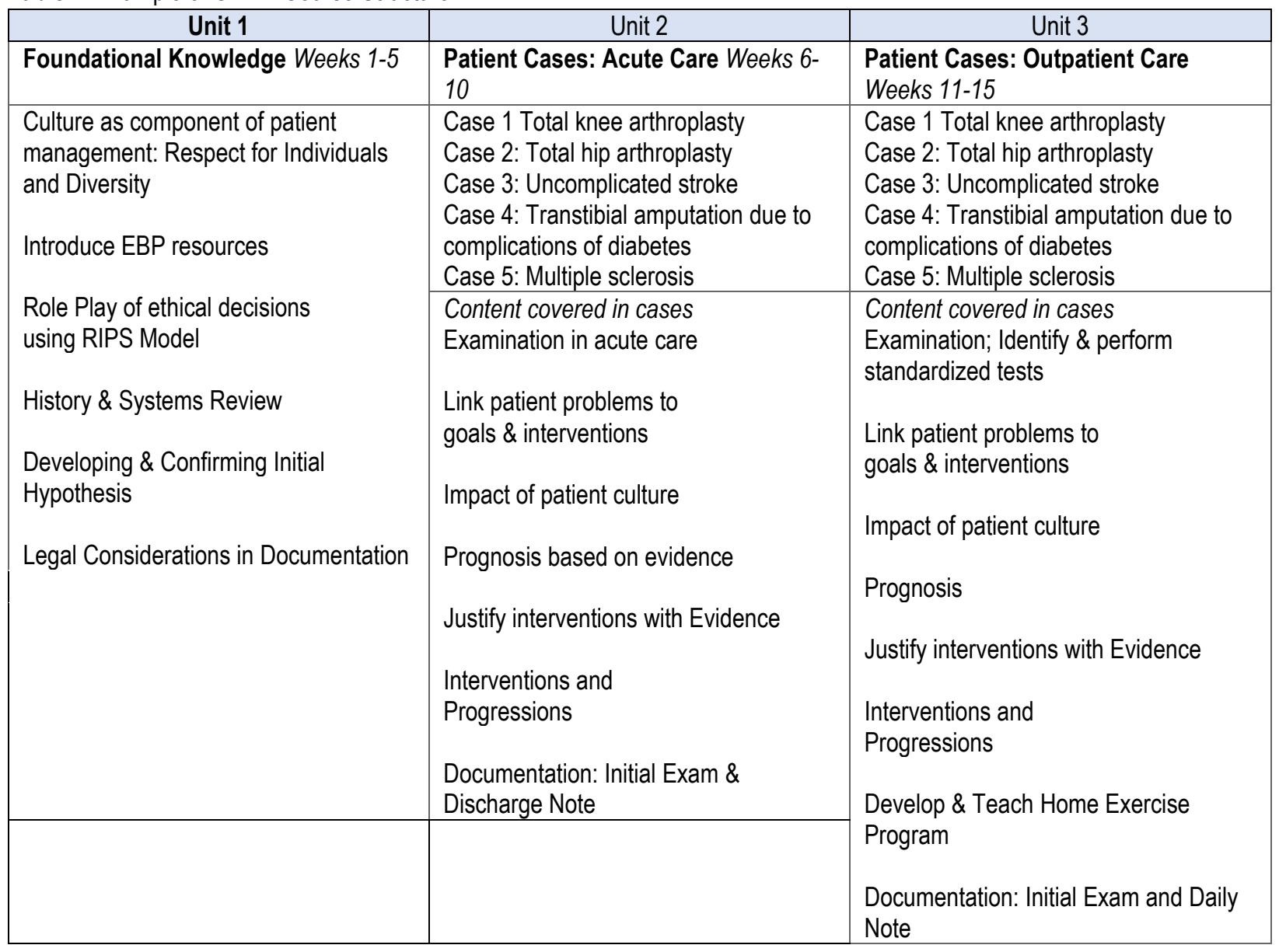

Evidence-Based Practice (EBP): Content about using evidence in practice was based on suggestions from the Doctor of Physical Therapy Education Evidence-Based Practice Curriculum Guidelines from the American Physical Therapy Association's (APTA) Section on Research. ${ }^{18}$ The chosen content included information initially taught in other classes such as asking focused clinical questions, searching for best available evidence, critically appraising and applying that evidence, and evaluating outcomes. In CDM-I and -II, learning experiences often were completed by small groups while in CDM-III and -IV individual assignments were used more often. Students participated in a journal club to experience professional discussions about scientific literature. The use of current best evidence, the clinician's knowledge base and judgment, and the patient's values and needs were incorporated when making clinical decisions about the best diagnostic tests and measures and intervention strategies into patient cases.

Ethics and Legal Responsibilities: Legal and ethical issues were discussed within the context of clinical decisions made in cases presented in class. The model of ethical decision-making used in the CDM sequence was described by Swisher, Arslanian, and Davis as the Realm-Individual-Process-Situation (RIPS) Model. ${ }^{19}$ The three realms of ethics are the individual, the organization, and society all of which exist in almost every ethical problem, although one may be more predominant than the others depending on the situation. The four components of moral behavior include moral sensitivity, moral judgment, moral motivation, and moral courage. Ethical situations that may be encountered in health care are ethical issues or problems, dilemmas, distress, temptation, and silence. Students practiced analyzing cases using the RIPS model. ${ }^{19}$

Step 7 Select or create a teaching strategy. The teaching strategy was built on patient management from the initial examination through discharge. For each course the diagnoses and venue of care was chosen based on what students were learning concurrently in other coursework. This strategy was chosen to integrate and synthesize content taught in other classes, guided by a patient management process used clinically. There were a minimal number of short lectures and most of the classroom time was spent in active problem-solving focused on patient cases. 
Step 8 Integrate the course structure and the instructional strategy to create an overall scheme of learning activities. The themes used to integrate the courses were interwoven within the patient cases as much as possible, although some content was presented in a more stand-alone manner.

\section{STUDENT OUTCOMES}

To study the outcomes of the CDM course-sequence design, two types of student-oriented measures were chosen because they supported a multidimensional definition of clinical reasoning and because they were part of regular assessments used in the program. The first method of assessing first-year student learning in the CDM I course incorporated ratings of self-confidence in making clinical decisions in a practical examination. The second method used clinical instructors' ratings of third-year student performance in a full-time clinical experience.

For the first outcome, students reflected on their level of self-confidence and self-perceived strengths and weaknesses in their preparation for a practical examination in Examination Techniques, a course that the students were enrolled in concurrently with CDM I. One week prior to the Examination Techniques midterm practical examination, students were asked five reflective questions to assess their readiness for the practical examination. This was a regular assignment in CDM I and was designed to allow the students to practice self-reflection. One question that the students answered in the assignment was "Rate how confident are you right now about your ability to make correct clinical decisions in the midterm practical exam?" Immediately following the practical, students were asked to reflect on how they performed in the examination. One question that students answered immediately after the practical was "Rate how confident you were in your ability to make correct clinical decisions during the practical." The same rating scale was used for both reflections, which was an 11-point scale bounded on either end with the descriptors " 0 , Not confident at all" and "10, Completely confident".20

The second outcome occurred during a full-time clinical experience. After two years of didactic coursework, students in this professional program completed 32 weeks of full-time clinical education experiences (CE) in four separate settings. The first fulltime CE course was eight-weeks in length and could occur in a variety of clinical settings and locations. During this clinical experience, clinical instructors used the Physical Therapist Manual for the Assessment of Clinical Skills (PT MACS) to evaluate the students' performance. ${ }^{21}$ The PT MACS is a standardized assessment of clinical practice which defines skills required for safe and effective physical therapist practice and which was developed by and is used by members of the Texas Consortium for Physical Therapist Clinical Education. ${ }^{21}$ Each one of 22 skills include specific objectives which must be rated individually for the entire skill to be completed successfully. See Table 2. Each skill includes specific behavioral objectives which are rated on a four-point scale from "Above Entry-Level" to "Unacceptable". ${ }^{21}$ See Table 3.

Table 2. Objectives of Selected Skills from the PT MACS ${ }^{21}$

\begin{tabular}{|c|c|}
\hline Skill & Objectives \\
\hline $\begin{array}{l}\text { Skill 2: Commitment to } \\
\text { Learning }\end{array}$ & $\begin{array}{l}\text { Demonstrates willingness to evaluate own performance. } \\
\text { Identifies problems and information/learning needs. } \\
\text { Seeks and utilizes appropriate resources to facilitate learning. } \\
\text { Incorporates new knowledge into professional practice. }\end{array}$ \\
\hline $\begin{array}{l}\text { Skill 3: Interpersonal } \\
\text { Skills }\end{array}$ & $\begin{array}{l}\text { Maintains professional demeanor in all interactions. } \\
\text { Demonstrates respect for all persons (including respect for differences in age, gender, race, } \\
\text { nationality, religion, ethnicity, social or economic status, lifestyle, health or disability status, or } \\
\text { learning style). } \\
\text { Interacts appropriately to establish rapport and trust with others. } \\
\text { Responds appropriately to unexpected situations. }\end{array}$ \\
\hline $\begin{array}{l}\text { Skill 6: Use of } \\
\text { Constructive Feedback }\end{array}$ & $\begin{array}{l}\text { Assesses own performance accurately. } \\
\text { Seeks feedback. } \\
\text { Demonstrates positive attitude toward feedback. } \\
\text { Incorporates feedback into future experiences. } \\
\text { Provides appropriate feedback to others, including modification of feedback according to recipient's } \\
\text { needs. }\end{array}$ \\
\hline Skill 9: Problem Solving & $\begin{array}{l}\text { Identifies and states problem clearly. } \\
\text { Prioritizes problems. } \\
\text { Considers assets, limitations, and resources. } \\
\text { Identifies possible solutions and probable outcomes. } \\
\text { Implements solutions. } \\
\text { Evaluates outcomes and makes revisions as needed. }\end{array}$ \\
\hline
\end{tabular}

(c) The Internet Journal of Allied Health Sciences and Practice, 2019 


\begin{tabular}{|l|l|}
\hline \multicolumn{1}{|c|}{ Skill } & \multicolumn{1}{c|}{ Objectives } \\
\hline Skill 10: Critical & Articulates relevant questions and ideas. \\
Thinking & Synthesizes all available information. \\
& Examines currently accepted practices within context of scientific method. \\
& Formulates solutions to questions. \\
& Examines outcomes of the selected and alternative solutions. \\
\hline
\end{tabular}

Table 3. PT MACS Rating Scale 21

According to current standards of practice, the student's performance is:

$+\quad$ Above entry-level. Surpasses entry-level standards for this setting by meeting all applicable objectives; practices the skill safely, effectively, consistently, and efficiently.

$\sqrt{ } \quad$ Entry-level. Meets entry-level standards for this setting by meeting all applicable objectives; practices the skill safely and effectively.

$\mathrm{NI}$ Not Independent. Below entry-level standards for this setting; does not meet all applicable objectives; practices the skill with supervision or assistance from the $\mathrm{Cl}$ requiring guidance and/or correction.

U Unacceptable. Well below entry-level standards for this setting; does not meet applicable objectives even with repeated assistance from $\mathrm{Cl}$ to correct deficits; practice the skill in an unsafe and/or ineffective manner even with repeated guidance from $\mathrm{Cl}$.

Blank. Student has had no opportunity to practice the skill in this setting.

$\mathrm{KEY}: \mathrm{Cl}=$ clinical instructor

The five skills from the PT MACS used in the second measure of student outcomes were: Commitment to Learning, Interpersonal Skills, Use of Constructive Feedback, Problem-Solving, and Critical Thinking. The Director of Clinical Education provided the midterm and final ratings for these skills to the researcher, omitting student names. These five skills were chosen because the skill description and associated behavioral objectives contain important components of clinical reasoning. The students' performance in a clinical setting reflected the impact of the entire curriculum and cannot be attributed solely to the CDM courses; however, using an authentic assessment of clinical reasoning was one way to determine the extent of the students' clinical reasoning skills. Because it is difficult, if not impossible, to separate the effects of the didactic and clinical components of professional preparation, an audit of these five skills was completed at midterm and the conclusion of only the first full-time clinical experience in order to try to minimize the cumulative effects of clinical education and to determine the extent of change that resulted in participating in the first clinical experience.

\section{RESULTS}

Practical Self-Assessment: Descriptive statistics and a t-test were used to analyze the ratings of self-confidence about clinical reasoning before and after the midterm practical exam in the Examination Techniques course. A total of 41 first-year students ranked their confidence in making clinical decisions both before and after the practical. The mean ratings for self-confidence in the ability to make clinical decisions was 5.41 (out of 10) in the pre-practical assessment and 7.27 in the post-practical assessment. The range of the rating was 3-9 in both the pre-practical and post-practical assessment. A paired t-test found a significant difference $\left(.05 t_{40}=-6.66, \rho=0.00\right)$ in the mean change in ratings of students from the pre-practical assessment to the post-practical assessment of confidence in making clinical decisions. See Table 4.

Table 4. Outcomes of Self-Assessment of Clinical Decisions in Practical Exam

\begin{tabular}{|l|r|r|}
\hline & Pre-Practical Assessment & Post-Practical Assessment \\
\hline Mean & 5.41 & 7.27 \\
\hline Range & $3-9$ & $3-9$ \\
\hline Variance & 2.15 & 1.80 \\
\hline Observations & 41 & 41 \\
\hline $.05 t 40$ & -6.66 & \\
\hline$\rho$-value & 0.00 & \\
\hline
\end{tabular}

PT MACS Skills: Frequencies were calculated for the ratings on the five skills audited in the PT MACS at the midterm and final assessment during the first full-time clinical experience of third year DPT students. Most students received ratings that met or exceeded expectations (check or plus) on the audited skills from the PT MACS, both at midterm and at the final assessment. At midterm, the frequencies for "plus" ratings varied from $0 \%$ on Skill 9: Problem Solving and Skill 10: Critical Thinking to $7.5 \%$ on 
Skill 3: Interpersonal Skills. The frequencies for "check" ratings at midterm varied from $60 \%$ on Skill 9: Problem Solving to $92.5 \%$ on Skill 2: Commitment to Learning and Skill 6: Use of Constructive Feedback. At the final assessment, frequencies for "plus" ratings varied from $0 \%$ on Skill 10: Critical Thinking to $22.5 \%$ on Skill 3: Interpersonal Skills. The frequency for "check" ratings at the final assessment varied from 75\% on Skill 9: Problem Solving to $95 \%$ on Skill 6: Use of Constructive Feedback. The Chi-Square Test of Independence ( $\alpha=.05)$ was used to identify any differences between midterm and final ratings of the five audited skills. No significant differences between midterm and final ratings on any of the selected skills was found. See Table 5.

Table 5. Results of Chi-Square Test of Independence in Selected Skill Ratings in CE 1

\begin{tabular}{|c|c|c|c|c|}
\hline PT MACS Skill 21 & Ratings & $\begin{array}{l}\text { CE } 1 \text { Midterm } \\
\text { Frequency } \\
\text { (Percent) }\end{array}$ & $\begin{array}{c}\text { CE 1 Final } \\
\text { Frequency } \\
\text { (Percent) }\end{array}$ & $\begin{array}{l}\text { Chi-Square Test of } \\
\text { Independence } \\
(\rho)\end{array}$ \\
\hline \multirow[t]{4}{*}{ Skill 2: Commitment to Learning } & Plus & $2 \quad(5 \%)$ & $8 \quad(20 \%)$ & \multirow[t]{4}{*}{$4.9623, \rho=0.17458$} \\
\hline & Check & $37 \quad(92.5 \%)$ & $32 \quad(80 \%)$ & \\
\hline & $\mathrm{NI}$ & $1 \quad(2.5 \%)$ & $0 \quad(0 \%)$ & \\
\hline & $U$ & $\begin{array}{ll}0 & (0 \%) \\
\end{array}$ & $0 \quad(0 \%)$ & \\
\hline \multirow[t]{4}{*}{ Skill 3: Interpersonal Skills } & Plus & $3 \quad(7.5 \%)$ & $9 \quad(22.5 \%)$ & \multirow[t]{4}{*}{$6.1385, \rho=0.10506$} \\
\hline & Check & $34 \quad(85 \%)$ & $31 \quad(77.5 \%)$ & \\
\hline & $\mathrm{NI}$ & $3 \quad(7.5 \%)$ & $0 \quad(0 \%)$ & \\
\hline & U & $0 \quad(0 \%)$ & $0 \quad(0 \%)$ & \\
\hline \multirow{4}{*}{$\begin{array}{l}\text { Skill 6: Use of Constructive } \\
\text { Feedback }\end{array}$} & Plus & $1 \quad(2.5 \%)$ & $2 \quad(5 \%)$ & \multirow[t]{4}{*}{$2 . .3468, \rho=0.50364$} \\
\hline & Check & $37 \quad(92.5 \%)$ & $38 \quad(95 \%)$ & \\
\hline & $\mathrm{NI}$ & $2 \quad(5 \%)$ & $0 \quad(0 \%)$ & \\
\hline & $\mathrm{U}$ & $\begin{array}{ll}0 & (0 \%) \\
\end{array}$ & $0 \quad(0 \%)$ & \\
\hline \multirow[t]{4}{*}{ Skill 9: Problem Solving } & Plus & $0 \quad(0 \%)$ & $2 \quad(5 \%)$ & \multirow[t]{4}{*}{$5.3333, \rho=0.14895$} \\
\hline & Check & $\begin{array}{ll}24 & (60 \%)\end{array}$ & $\begin{array}{ll}30 & (75 \%)\end{array}$ & \\
\hline & $\mathrm{NI}$ & $16 \quad(40 \%)$ & $8 \quad(20 \%)$ & \\
\hline & $\mathrm{U}$ & $(0 \%)$ & $0 \quad(0 \%)$ & \\
\hline \multirow[t]{4}{*}{ Skill 10: Critical Thinking } & Plus & $(0 \%)$ & $(0 \%)$ & \multirow[t]{4}{*}{$1.6142, \rho=0.65617$} \\
\hline & Check & $(67.5 \%)$ & $(80 \%)$ & \\
\hline & $\mathrm{NI}$ & $(32.5 \%)$ & $(20 \%)$ & \\
\hline & $U$ & $(0 \%)$ & $\begin{array}{ll}0 & (0 \%)\end{array}$ & \\
\hline
\end{tabular}

\section{DISCUSSION}

Self-reflection is a commonly identified trait of expert practice and clinical reasoning. Reflecting on actions taken allows the practitioner to develop advanced clinical reasoning skills by learning from experience. Confidence in one's abilities in a specific situation, or self-efficacy, is another facet of clinical reasoning and expert practice. ${ }^{3,4}$ The reflection assignment associated with the practical exam incorporated questions about self-confidence in clinical reasoning. Asking students to reflect immediately after the practical provided students with the opportunity to pause and reflect on their strengths and weakness in clinical reasoning. This outcome was selected because confidence in one's abilities in a specific situation, or self-efficacy, is a facet of clinical reasoning and expert practice. ${ }^{8,22}$ The significant change in students' confidence in their ability to make clinical decisions before and after a practical examination reflected a change in their confidence in their own abilities and not necessarily a change in their actual abilities to make clinical decisions.

The lack of a significant difference in ratings of PT MACS skills within one full-time clinical experience may be interpreted in more than one way. First an assumption could be made that the chosen skills did not adequately measure clinical reasoning. However, the skills represented important professional behaviors that meet many of the components in the CRARC definition of clinical reasoning:

"Clinical reasoning is a nonlinear, recursive cognitive process (Commitment to Learning) in which the clinician synthesizes information (Problem Solving) collaboratively with the patient, caregivers, and the health care team (Interpersonal Skills) in the context of the task and the setting. The clinician reflectively integrates information (Use of Constructive Feedback) with previous knowledge and best available evidence in order to take deliberative action (Critical Thinking)."2 (PT MACS skills in parentheses added by the author). 
Specific objectives from Skill 2 (Commitment to Learning) that are directly related to clinical reasoning and decision making include demonstrating willingness to evaluate one's performance; identifying problems and learning needs; and incorporating new knowledge into professional practice. The objectives from Skill 3: Interpersonal skills that are most closely align with the consensus definition of clinical reasoning are demonstrating respect for all persons; interacting appropriately to establish rapport and trust with others; and responding appropriately to unexpected situations. Also closely aligned with the definition of clinical reasoning are three objectives from Skill 6: Use of Constructive Feedback: assessing own performance accurately; seeking and demonstrating a positive attitude toward feedback; and incorporating feedback into future experiences. All the objectives from Skill 9: Problem Solving are included in clinical reasoning identifying and stating problems clearly; prioritizing problems; considering assets, limitations, and resources; identifying possible solutions and probable outcomes; implementing solutions; and evaluating outcomes and making revisions as needed. Finally, pertinent objectives from Skill 10: Critical Thinking are: articulating relevant questions and ideas; synthesizing all available information; examining currently accepted practices; formulating solutions to questions; and examining outcomes of selected and alternative solutions. ${ }^{21}$ Because of the close alignment between objectives and the CRARC definition of clinical reasoning it is unlikely that the lack of significant differences between the midterm assessment and the final assessment of clinical skills was due to an inability of the PT MACS to measure clinical reasoning or differences in performance over time.

A second interpretation could be that no improvement in clinical reasoning or in the five individual skills occurred from week four to week eight of the clinical experience. Although there was not a significant difference in the two sets of ratings, there was a trend of improvement in the number of "plus" and "check" ratings in the five selected skills. Most notably there was an overall shift toward more ratings indicating meeting or exceeding expectations and fewer ratings in the "needs improvement" category. It is also notable that there were no ratings of "unsatisfactory" in any skill at the midterm or final evaluation. Finally, it is reasonable to expect less drastic improvement in a clinical education experience where students are practicing with "real" patients who have complex impairments and functional limitations as well as cultural contexts which can impact care more than in an artificial classroom setting.

In applying Fink's model to the four courses in the CDM sequence, several changes occurred compared to how these courses had been previously taught. Prior to applying Fink's model, the CDM courses did not have any unifying themes and were sometimes used to teach topics that were not focused on clinical decision-making, but that didn't "fit" in other courses in the curriculum. Clinical reasoning is a process and so it should be expected that the development of competence in clinical reasoning requires time, focused practice, and feedback. Student learning is driven by what the program curriculum and faculty emphasize. ${ }^{13}$ Providing four courses within the program curriculum allows development of clinical reasoning to occur and demonstrates faculty commitment to the concepts taught in the courses. Because the CDM courses were intended to synthesize already-presented material, using Fink's model was ideal to use to provide time, practice, and feedback to the students as they developed clinical reasoning and decision-making skills.

Another change was that the focus of all teaching strategies within and among the four courses were on the various components of patient management. There was less emphasis on lecturing over content and more emphasis on active learning experiences in which students practiced skills they would use in professional practice such as examination and intervention strategies, using evidence to make decisions, and documentation of patient care.

The sequence of CDM courses had five significant learning goals which represented each of the six dimensions of learning in Fink's taxonomy. ${ }^{10}$ The primary goal of the sequence was to enhance the clinical reasoning skills and quality of clinical decisions made by students. The significant learning goals for the sequence are what the instructor wanted students to retain after the course was over and which changed the students in a real and long-lasting manner. The five significant learning goals for the sequence included all components of Fink's taxonomy for significant learning. Using a single set of goals for the four-course sequence helped to unify the courses and provided links to learning experiences that provided active practice of tasks that are expected of graduates of physical therapy professional programs.

\section{LIMITATIONS}

Limitations of the described course sequence design include the amount of time and energy devoted to teaching four separate courses in clinical reasoning in a professional physical therapist program. Not every program will have the time and credit hours described to devote to clinical reasoning and decision-making as stand-alone courses. Because significant learning approaches were built around specific subject content and learning contexts, the courses described in this paper may not be reproducible as a teaching plan, but the process and content may be used as a model for other clinical reasoning courses, including those outside the profession of physical therapy. This paper serves as an example of how Fink's process of creating significant learning experiences can be used to teach clinical reasoning and decision-making to health professions students.

( The Internet Journal of Allied Health Sciences and Practice, 2019 


\section{CONCLUSIONS}

The course designs described offer specific details about how one method of teaching clinical reasoning meets the current trends in education and health care for accountability and meaningful outcomes. ${ }^{13}$ Students gained practical knowledge and skills in the components of clinical reasoning and decision-making by participating in active and engaging significant learning experiences. The courses were unified by four themes and two models of practice for patient management. This paper presented one design for teaching clinical reasoning in a professional physical therapist education program. It is unique in its comprehensive quality and in how it is incorporated into a professional curriculum through four separate courses. The process described by Fink could be used in other health care professional programs to teach clinical reasoning and decision-making skills. The process described a method to thoughtfully and deliberately design courses to include significant learning experiences and to change students in a real and long-lasting manner as they develop into expert clinicians after graduation.

\section{REFERENCES}

1. Jensen GM, Shepard KF, Hack LM. The novice versus the experienced clinician: insights into the work of the physical therapist. Phys Ther. 1990;70(5):314-323. doi:10.1093/ptj/70.5.314 [PMID: 2333330]

2. Christensen N, Black L, Furze J, Huhn K, Vendrely A, Wainwright S. Clinical reasoning: survey of teaching methods, integration, and assessment in entry-level physical therapist academic education. Phys Ther. 2017;97(2):175-186. doi:10.2522/ptj.20150320 [PMID 27609900]

3. Christensen N, Jones MA, Edwards I, Higgs J. Helping physiotherapy students develop clinical reasoning capability. In: Higgs J, Jones MA, Loftus S, Christensen N, eds. Clinical Reasoning in the Health Professions. 3rd ed. Boston, MA: Butterworth Heinemann Elsevier; 2008:389-396.

4. Jones MA, Jensen G, Edwards I. Clinical reasoning in physiotherapy. In: Higgs J, Jones MA, Loftus S, Christensen N, eds. Clinical Reasoning in the Health Professions. 3rd ed. Boston, MA: Elsevier; 2008:245-256.

5. Guide to physical therapist practice 3.0. American Physical Therapy Association Web site. http://guidetoptpractice.apta.org/. Published 2014. Accessed October 12, 2016.

6. Rothstein JM, Echternach JL, Riddle DL. The hypothesis-oriented algorithm for clinicians II (HOAC II): a guide for patient management. Phys Ther. 2003;83(5):455-470. doi:10.1093/pt//83.5.455 [PMID 12718711]

7. World Health Organization. International classification of functioning, disability, and health. http://www.who.int/classifications/icf/en/. Updated December 16, 2015. Accessed June 29, 2016.

8. Ryan S, Higgs J. Teaching and learning clinical reasoning. In: Higgs J, Jones MA, Loftus S, Christensen N, eds. Clinical Reasoning in the Health Professions. 3rd ed. Boston, MA: Butterworth Heinemann Elsevier; 2008:379-388.

9. Bandura A. Guide for constructing self-efficacy scales. In: Pajares F, Urdan T, eds. Self-Efficacy Beliefs of Adolescents. Greenwich, CT: Information Age Publishing; 2006: 307-337.

10. Fink LD. Creating significant learning experiences: An integrated approach to designing college courses. San Francisco, CA: Jossey-Bass; 2003.

11. Guttikonda RR, Coco CM. Incorporating Fink's significant learning experience model in the re-designing of the flagship accounting course. J Account Finance. 2013;13(5):112-120.

12. Hurtubise L, Roman B. Competency-based curricular design to encourage significant learning. Curr Probl Pediatr Adolesc Health Care. 2014;44(6):164-169. doi:10.1016/j.cppeds.2014.01.005

13. Levine LE, Fallahi CR, Nicoll JM, Tessier JT, Watson CL, Wood RM. Creating significant learning experiences across disciplines. College Teaching. 2008;56(4):247-254. doi:10.3200/CTCH.56.4.247-254

14. Bethards ML. Applying social learning theory to the observer role in simulation. Clin Simulation Nurs. 2014;10(2):e65-69. doi:10.1016/j.ecns.2013.08.002 
15. Grignon TP, Henley E, Lee KM, Abentroth MJ, Jette DU. Expected graduate outcomes in US physical therapist education programs: a qualitative study. J Phys Ther Educ. 2014;28(1):48-57. [PMID 104014765]

16. Jewell DV. Evidence-based physical therapist practice. In: Jewell DV. Guide to Evidence-Based Physical Therapist Practice. 4th ed. Burlington, MA: Jones \& Bartlett Learning; 2018:9.

17. Institute of Medicine. Crossing the Quality Chasm: A New Health System for the 21st Century. 2001. Washington, DC: The National Academies Press. https://doi.org/10.17226/10027.

18. Levine D, Tilson JK, Fay D, et al. Doctor of physical therapy education evidence-based practice curriculum guidelines. American Physical Therapy Association. Section on Research. http://www.ptresearch.org/site/1/SIGS/EBP/EBP\%20PT\%20ED\%20MANUAL\%20FINAL\%202-24-15.pdf. Published March 2014. Accessed June 1, 2015.

19. Swisher LL, Arslanian LE, Davis CM. The realm-individual-process-situation (RIPS) model of ethical decision-making. HPA Resource. 2005;5(3):1-8. Available at https://www.apta.org/uploadedFiles/APTAorg/Practice_and_Patient_Care/Ethics/Tools/RIPS_DecisionMaking.pdf

20. Stickley L, Gibbs K, Bachman T. Practical examination as a reflective learning tool for professional behaviors. J Health Sci Educ. 2018;2:130. doi:10.0000/JHSE.1000130 Available at http://escires.com/articles/Health-1-130.pdf

21. Dillon L, Gleeson P, Burgess N, Csiza L, Galloway R, Spivey S, eds. Physical Therapist Manual for the Assessment of Clinical Skills. 2nd ed. Fort Worth, TX: Texas Consortium for Physical Therapy Clinical Education Inc; 2015.

22. Wainwright SF, Shepard KF, Harman LB, Stephens J. Novice and experienced physical therapist clinicians: a comparison of how reflection is used to inform the clinical decision-making process. Phys Ther. 2010;90(1):75-88.

doi:10.2522/ptj.20090077 [PMID: 19926680 
Appendix A. Course Learning Objectives by Themes and Sequence Learning Goals

\begin{tabular}{|c|c|c|c|c|}
\hline $\begin{array}{c}\text { Theme \& } \\
\text { Sequence } \\
\text { Learning } \\
\text { Goals }\end{array}$ & $\begin{array}{l}\text { CDM I } \\
\text { (Year1, Fall) } \\
\text { At the end of the } \\
\text { course, the student } \\
\text { will be able to: }\end{array}$ & $\begin{array}{l}\text { CDM II } \\
\text { (Year1, Spring) } \\
\text { At the end of the } \\
\text { course, the student } \\
\text { will be able to: }\end{array}$ & $\begin{array}{l}\text { CDM III } \\
\text { (Year2, Fall) } \\
\text { At the end of the } \\
\text { course, the student } \\
\text { will be able to: }\end{array}$ & $\begin{array}{l}\text { CDM IV } \\
\text { (Year2, Spring) } \\
\text { At the end of the } \\
\text { course, the student } \\
\text { will be able to: }\end{array}$ \\
\hline $\begin{array}{l}\text { Model of } \\
\text { practice } \\
\text { (1) } \\
\text { demonstrat } \\
\text { e clinical } \\
\text { reasoning } \\
\text { skills and } \\
\text { sound } \\
\text { clinical } \\
\text { decisions in } \\
\text { physical } \\
\text { therapist } \\
\text { practice; } \\
\text { (2) use a } \\
\text { model of } \\
\text { clinical } \\
\text { practice to } \\
\text { apply } \\
\text { current } \\
\text { knowledge } \\
\text { and skills } \\
\text { to patient } \\
\text { cases }\end{array}$ & $\begin{array}{l}\text { - Analyze patient } \\
\text { cases using the } \\
\text { ICF and } \\
\text { HOAC-II. } \\
\text { - Provide } \\
\text { meaningful } \\
\text { feedback to } \\
\text { peers. } \\
\text { Identify } \\
\text { interprofessiona } \\
1 \text { team members } \\
\text { associated with } \\
\text { cases. }\end{array}$ & $\begin{array}{l}\text { - Analyze patient } \\
\text { cases using the } \\
\text { HOAC-II from } \\
\text { observations of } \\
\text { expert } \\
\text { practitioners' } \\
\text { management of } \\
\text { pediatric } \\
\text { patients, } \\
\text { patients with } \\
\text { cardiopulmonar } \\
\text { y dysfunction, } \\
\text { and patients } \\
\text { with } \\
\text { musculoskeletal } \\
\text { dysfunctions of } \\
\text { the cervical } \\
\text { spine. } \\
\text { Provide } \\
\text { meaningful } \\
\text { feedback to } \\
\text { peers. }\end{array}$ & 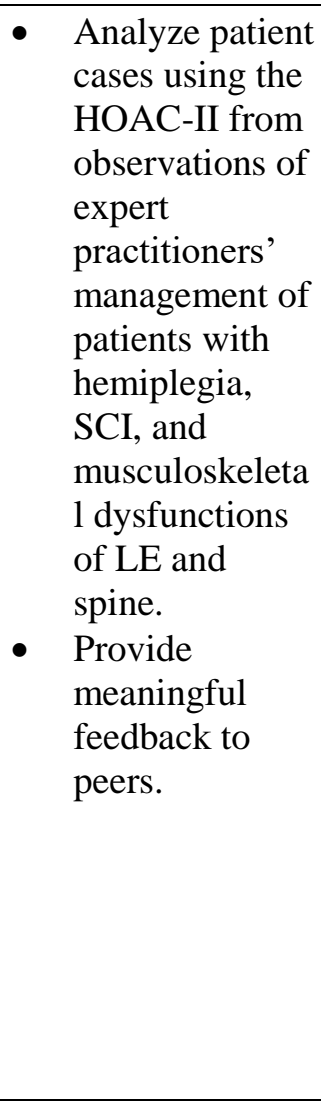 & $\begin{array}{l}\text { Analyze } \\
\text { patient cases } \\
\text { from a variety } \\
\text { of } \\
\text { backgrounds } \\
\text { and diagnoses } \\
\text { using the } \\
\text { HOAC-II. } \\
\text { - Provide } \\
\text { meaningful } \\
\text { feedback to } \\
\text { peers. }\end{array}$ \\
\hline 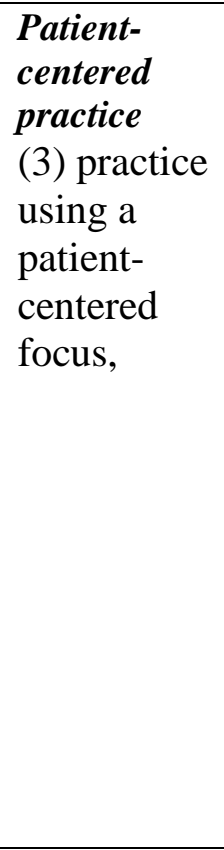 & 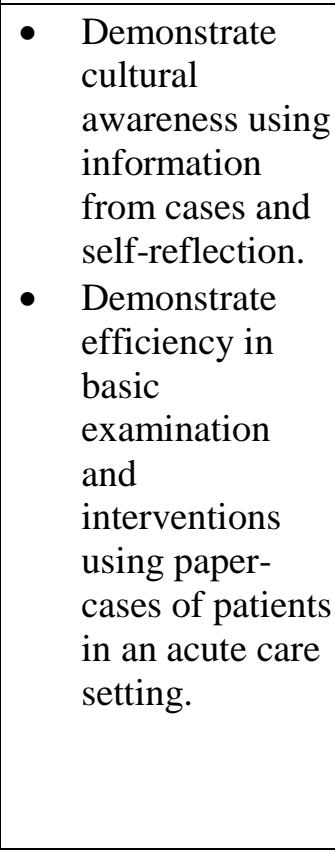 & $\begin{array}{l}\text { Demonstrate } \\
\text { behaviors } \\
\text { associated with } \\
\text { cultural } \\
\text { sensitivity. } \\
\text { Observe and } \\
\text { analyze the } \\
\text { patient } \\
\text { management } \\
\text { skills of an } \\
\text { expert } \\
\text { practitioner. } \\
\text { Demonstrate } \\
\text { efficiency in } \\
\text { examination and } \\
\text { intervention } \\
\text { techniques for } \\
\text { patients with } \\
\text { musculoskeletal }\end{array}$ & 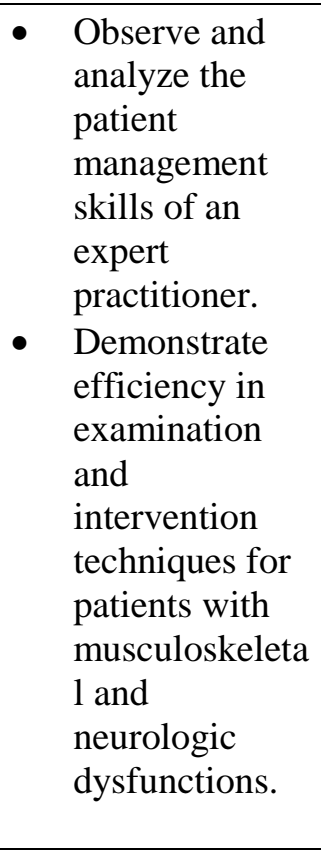 & $\begin{array}{l}\text { - Demonstrate } \\
\text { efficiency in } \\
\text { examination } \\
\text { and } \\
\text { intervention } \\
\text { techniques for } \\
\text { patients with a } \\
\text { variety of } \\
\text { diagnoses. } \\
\text { Value the } \\
\text { individual } \\
\text { experiences of } \\
\text { patients/clients } \\
\text { - Value the } \\
\text { cultural } \\
\text { backgrounds } \\
\text { of class } \\
\text { members and }\end{array}$ \\
\hline
\end{tabular}




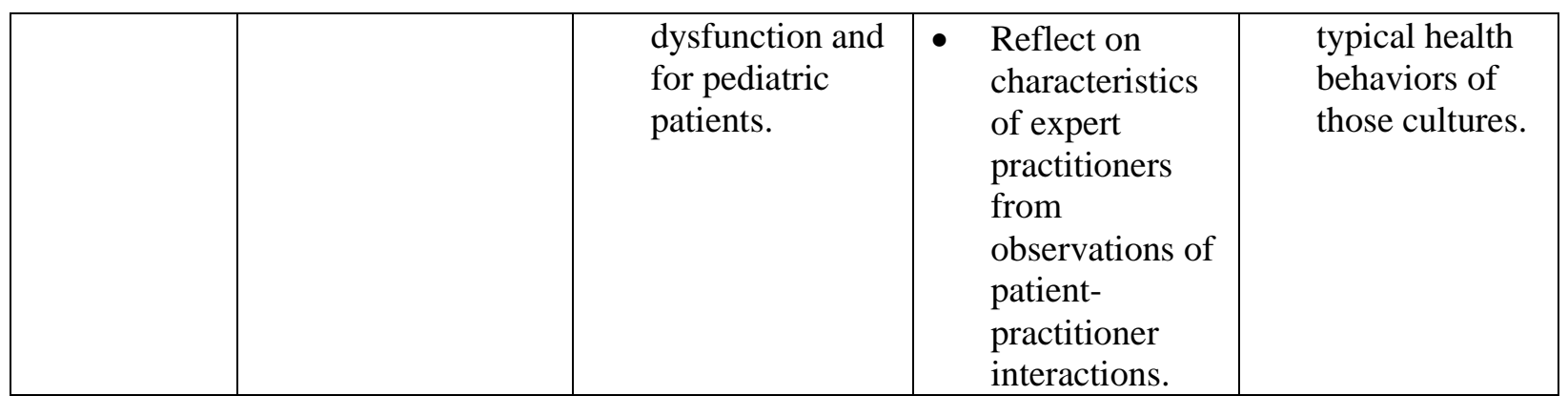




\section{Appendix B. CDM-I Worksheet}

1. Using the information you have learned about your patient case from the history and the results of the tests and measures, organize the data using the ICF.

\begin{tabular}{|l|}
\hline HEALTH CONDITION \\
\hline
\end{tabular}

\begin{tabular}{|c|c|}
\hline \multicolumn{2}{|c|}{ BODY STRUCTURES/FUNCTION } \\
\hline IMPAIRMENTS & RESOURCES (STRENGTHS) \\
\hline & \\
\hline
\end{tabular}

\begin{tabular}{|c|c|}
\hline \multicolumn{2}{|c|}{ ACTIVITY (TASKS) } \\
\hline Abilities & \\
\hline & \\
& \\
& \\
\hline
\end{tabular}

\begin{tabular}{|l|l|}
\hline \multicolumn{2}{|c|}{ PARTICIPATION } \\
\hline Abilities & \\
\hline & \\
& \\
\hline
\end{tabular}

\begin{tabular}{|l|l|l|l|}
\hline \multicolumn{5}{|c|}{ ENVIRONMENTAL } \\
\hline \multicolumn{2}{|c|}{ INTERNAL } & \multicolumn{2}{c|}{ EXTERNAL } \\
\hline FACILITATE FUNCTION & INHIBIT FUNCTION & FACILITATE FUNCTION & INHIBIT FUNCTION \\
\hline & & & \\
& & & \\
\hline
\end{tabular}

2. Categorize the problems the patient identified in the history (PIP) and the problems you identified from the tests and measures (NPIPS) using the ICF Model.

\begin{tabular}{|l|l|l|}
\hline ICF Component & Patient-Identified Problems & Non-patient-Identified Problems \\
\hline
\end{tabular}




\begin{tabular}{|l|l|l|}
\hline Impairments & & \\
\hline Activity Limitations & & \\
& & \\
\hline Participation & & \\
Restrictions & & \\
& & \\
\hline
\end{tabular}

3. Prioritize the 4 MOST IMPORTANT problems that can be corrected by PT. Which problem, if corrected, will impact the patient's function most positively?
a.
b.
c.
d.

4. Write 1 short-term goal to address each prioritized problem. The expected length of stay in the hospital is 3 days. You should have a total of 4 goals.
a.
b.
c.
d.

5. Provide an assessment using your professional judgment to summarize the patient's problems focusing on functional limitations. Use body function impairments to explain why the functional limitations exist and how participation is affected. This should demonstrate your clinical reasoning skills.

6. Determine a physical therapy diagnosis. (E.g. The patient presents with quadriplegia and sensory loss leading to dependency in bed mobility, transfers, and locomotion consistent with a C-7 spinal cord injury.) 